\title{
How to establish case registers: I. Suicide
}

\author{
J. Evans, C. Johnson, R. Stanton and H. G. Morgan
}

The importance of establishing case reglsters for suicide is discussed along with their potential uses. Suicide data can be dertived from the coroner, the District Health Authortly or the Olilice of Population Censuses and Surveys (OPCS). The relative mertts of these different data sources are discuseed and local methods described. Some data dertved from the suicide register are shown.

Preventing suicidal behaviour is a major challenge. The Health of the Nation (Department of Health, 1992) is a strategic report that sets targets for a $15 \%$ reduction of the general population suicide rates (the figures given are for suicide and undetermined deaths) and a 33\% reduction among the severely mentally ill by the year 2000. Suicide among young men rose by approximately $78 \%$ during the 1980 s (OPCS, 1991), and other vulnerable groups have been identified, including those recently discharged from psychiatric units and those with a history of deliberate self-harm.

Mental health services have been given an important role in suicide prevention: "The achievement of these targets depends upon the availability of psychiatric care that is costeffective and of the highest possible standard" (DoH, 1992). Although the responsibility for meeting these targets cannot belong to mental services alone, the challenge needs a response. Suicide rates are likely to become one of the main outcome indicators of mental health care provision.

In order to respond, we need to estimate the local population at risk of suicide, assess the existing provision for high risk groups and target resources appropriately. Any long-term strategles need to be underpinned by research aimed at defining effective clinical interventions that can be delivered and monitored within the service. In our view, the first step is to establish case registers.

Case registers are important to get a complete picture of the problem and are essential for audit and evaluation in any service. This paper describes our experience of establishing a case register for suicide, and we hope it will encourage others to do the same. Registers need not be too costly and time-consuming to be of value. We believe we have demonstrated that it is possible to set up such case registers with no significant additional resources.

\section{Data sources (Table 1)}

In developing a register a number of data sources of varying degrees of speed, accuracy, detail and convenience are available (Morgan, 1994).

\section{Informal reporting}

The suicide of a psychiatric patient may become known on the 'grapevine', but this will certainly exclude most of those who die without having had contact with mental health services.

\section{The coroner}

By law, every death occurring in England and Wales must be registered in the district in which it occurred, by the Registrar of Births, Deaths and Marriages. Sudden or unexpected death must be reported to the coroner for investigation before the death can be certified. In cases of suspected

Table 1. Potential data sources for suicide case register

\section{Informal}

Can be rapid. May have information to help judge 'clinical' suiclde. Incomplete.

Coroner - sudden and unexpected deaths

Inclusion of all possible clinical suicides. Rapld. Does not include those who Ive outside the area. Liaison with several coroners. Access to coroners' records needed to exclude obvious non-sulcides.

Coroner - suicide and open verdicts

Does not include those who Ilve outside the area. Liaison with several coroners. Will miss some 'clinical' suicides. District Heatth Authortilies

Single source of data. Relates to area. Possible delay in getting information particularly for those who die outside the area. Will miss 'clinical' sulcides.

Ofilice of Population Censuses and Surveys

Long delay. Expense. Useful for retrospective data collection. Will miss 'clinical' suicides. 
suicide an inquest will be held as part of the investigation. Waiting for the verdict of the inquest introduces a delay, in some rare cases, of a year or more. Information available on the circumstances of the death is held on file by the coroner. If access is permitted to these files it is possible to select cases in which the cause of death may have been suicide thus removing many non-suicides.

It should be noted that a single health district may overlap with several coroners' districts and that residents who die outside the district can be missed.

Coroners vary on their criteria for recording a suicide verdict. Including the category of 'undetermined death' reduces this variation considerably. In practice, most 'undetermined' deaths may be suicides, and are routinely included in suicide statistics. Locally, $32 \%$ of all verdicts are recorded as 'suicide' or 'undetermined' death.

\section{The District Health Authority (DHA)}

The DHAs are notified weekly by the Registrar of Births, Deaths and Marriages of all the deaths among the residents of their area. Such death certificates record the name, address, age, gender, date of death, cause of death, and the coroner's verdict if an inquest is held. Access to this information can be arranged by local DHA contacts. DHA data include those who died outside the area so are more complete than coroners' data, and all the information is available from one source. Most of these records are now held on computer and access to the data is easily obtained by an inquiry that matches verdicts. There may be a significant delay depending on local circumstances.

\section{The Office of Population Censuses and Surveys (OPCS)}

A further source is the OPCS which recelves weekly coples of all entries from all the Death Registers. This information is coded and stored and available through the OPCS. There is a charge for this information and also a delay between death and the availability of data.
Information can be obtained on cases by specifying the area of residence code and the ICD-E codes (WHO, 1978). This method would be most useful for retrospective data collection.

In Bristol we chose to compile a register for the whole of Avon including the four Trusts within Bristol and the DHA (Table 2). The method we have used is to identify, from files made available to us by the Coroner's Officer, all cases that could have been suicide. Verdicts are recorded as they become available and a register compiled. This is cross-checked with information provided by the DHA from their records of the death certificates of all Avon residents. In this way all cases, including those who die outside the county can be identified. Detalls are sent to those responsible for organising audit for each hospital. The audit coordinator can establish whether these individuals were under psychiatric supervision prior to suicide using hospital and community based information systems in the area and where available, registers of non-fatal deliberate selfharm. Audit meetings are held at regular intervals; at these meetings the main points of the clinical history are presented by the relevant consultant and any difficulties which occurred during the patient's management are identified. The discussion is summarised and the main points noted. Actions taken as a result of these points are reported back to future meetings. In this way information is accumulated based on the wider experience of the group rather than the narrow and possibly atypical experience of the individual clinician.

As we include all potential suicides, the occasional patient or ex-patient whose death receives an 'accidental' verdict will also be identified. Clinicians may suspect that some of these deaths are intentional (so called clinical suicides') and may choose to audit these cases in the same way as those given suicide or undetermined death verdicts.

\section{Comment}

In view of the low base rate, it would be easy to become defeatist about the feasibility of suicide

Table 2. Avon residents: case register of suicide and open verdicts (1993)

\begin{tabular}{|c|c|c|c|}
\hline & Mole & Female & Total \\
\hline \multicolumn{4}{|l|}{ Total number of inquests identified by Coroner's Officer } \\
\hline as beling of relevance & 112 & 34 & 146 \\
\hline Total number of suicide verdicts & 44 & 12 & 56 \\
\hline Total number of open verdicts & 19 & 9 & 28 \\
\hline $\begin{array}{l}\text { Total number of all verdicts identifled as having } \\
\text { contact with the psychlatric services } \\
\text { Total number of sulcide and open verdlcts identified }\end{array}$ & 51 & 9 & 60 \\
\hline as having contact with the psychlatric services & 30 & 6 & 36 \\
\hline
\end{tabular}


prevention, but The Health of the Nation charges us all with the duty to act. Collecting data in the form of case registers enables us to continue refining our understanding of risk factors for suicide and how these can change over time. We need to address suicide prevention for psychiatric patients, including the high risk period on discharge from hospital, and the role that malignant alienation may play (Watts \& Morgan, 1994): the Care Programme Approach may improve our response to these individuals. We must also devise means of reaching out to those who will die without having had contact with mental health services or their general practitioners. By auditing suicide in a systematic way clinical decision-making will be based on pooled experience not just on the cliniclan's memory of one or two cases. Comprehenstve registers of suicide provide clinictans with the opportunity of reviewing all cases in which they have had clinical involvement, so increasing the reliability of clinical experience. Overall, we need an attitude of vigilance about suicide risk, and of enthusiasm about pursuing initiatives based on research and clinical experience.

(Discussion of confidentiality and manpower will be found in part II and the references at the end of part II)

\title{
How to establish case registers: II. Non-fatal deliberate self-harm
}

\author{
J. Evans, C. Johnson, R. Stanton and H. G. Morgan
}

\begin{abstract}
The importance of cetcblithing registers for non-fotal dellberate selt-horm is cliscusesed along with their potentilat uses. Dellberate sell-harm (DSH) data for a single hoeplitel con bo dertved from the Accident and Emergency (ARE) casuctly cords, AaE on-line reglaters, mental hocith asecesements or general hoeplital in-patient detla. Tho relattve mertts of thees dillerent data sources are discusesed and locel methodis deecribed. Some data destred from the DSH regiter cre shown.
\end{abstract}

Patients who deliberately but non-fatally selfharm (DSH), utilise approximately 300 patientyears of acute care annually in England and Wales (Owens, 1990); in one study, 2.8\% had died by suicide within eight years of an attempt (Hawton \& Fagg, 1988). The costs to the individuals, their social networks, and the health service are enormous; and yet, in spite of extenstve research, we are little further forward in identifying those at greatest risk, defining effective intervention strategles, or planning service provision based on research data. This paper describes a method of establishing a hospital-based reglster of DSH for use in audit and research.
Table 1. Sources of data for DSH register

\begin{tabular}{|c|}
\hline 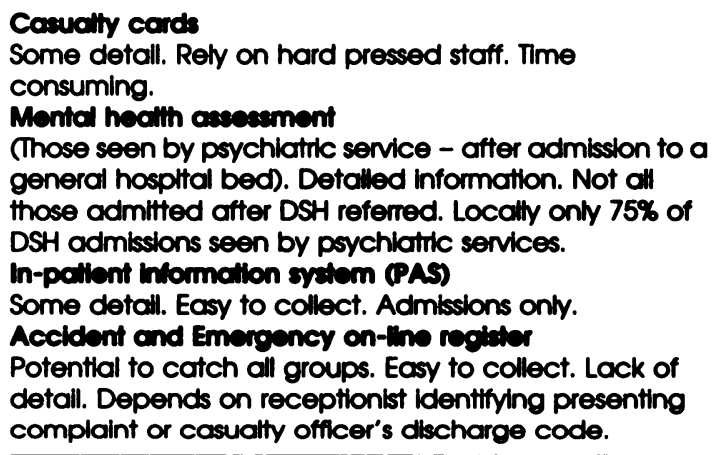 \\
\hline
\end{tabular}

\section{Data sources (Table I)}

Mental health assessments of those admitted following deliberate self-harm

A local audit indicated that $75 \%$ of those admitted following an episode of DSH are seen for a mental health assessment within 24 hours of admission. This provides an easily collected record, with 